\title{
Comparison of clinical outcomes in clomiphene citrate resistant infertile polycystic ovarian syndrome women after treatment with laparoscopic ovarian drilling (LOD) versus gonadotropins
}

\author{
Kumari Rupa ${ }^{1}$, Kanika Jain ${ }^{2}$, Debasis Dutta ${ }^{2}$, Shweta Mittal Gupta ${ }^{1}$, Kanika Chopra ${ }^{2 *}$
}

\begin{abstract}
${ }^{1}$ Department of Obstetrics and Gynecology, Sir Ganga Ram Hospital, New Delhi, India
${ }^{2}$ Department of Minimal Invasive Gynecology, Institute of Obstetrics and Gynecology, Sir Ganga Ram Hospital, New Delhi, India
\end{abstract}

Received: 22 November 2017

Accepted: 22 December 2017

\author{
*Correspondence: \\ Dr. Kanika Chopra, \\ E-mail:kank2kanu@yahoo.co.in
}

Copyright: ( ) the author(s), publisher and licensee Medip Academy. This is an open-access article distributed under the terms of the Creative Commons Attribution Non-Commercial License, which permits unrestricted non-commercial use, distribution, and reproduction in any medium, provided the original work is properly cited.

\begin{abstract}
Background: Infertility is the inability of a sexually active, non-contracepting couple to achieve pregnancy in one year. Objective of present study was to compare the clinical outcome of laparoscopic ovarian drilling with gonadotropin ovulation induction in patients with clomiphene resistant Polycystic Ovarian Syndrome.

Methods: Present study was a comparative interventional study conducted at the Institute of Obstetrics and Gynaecology, Sir Ganga Ram Hospital, New Delhi for a period of one and a half year. We enrolled 40 clomiphene citrate resistant infertile PCOS women who were undergoing treatment for infertility, after taking written informed consent. The women were randomly divided into two equal groups: one for LOD (laparoscopic ovarian drilling) (group A) and other for gonadotropins (group B).

Results: Out of 20, 16 women (80\%) in group A ovulated with clomiphene citrate and 18 women (90\%) ovulated in group B. Pregnancy was the second major outcome and 4 women $(20 \%)$ in group A with clomiphene citrate got pregnant and 9 women $(45 \%)$ got pregnant in group B.

Conclusions: Out of 20,16 women $(80 \%)$ in group A ovulated with clomiphene citrate and 18 women $(90 \%)$ ovulated in group B. Pregnancy was the second major outcome and 4 women (20\%) in group A with clomiphene citrate got pregnant and 9 women $(45 \%)$ got pregnant in group B. The treatment option can be selected and tailored according to the individual needs and desires of the patient.
\end{abstract}

Keywords: Gonadotropins, Infertility, Laparoscopic ovarian drilling, Polycystic ovarian syndrome

\section{INTRODUCTION}

Infertility is the inability of a sexually active, noncontracepting couple to achieve pregnancy in one year. This problem affects $10-15 \%$ of young couples around the world. ${ }^{1,2}$ Polycystic ovarian syndrome (PCOS) is the commonest cause of anovulatory infertility, affecting 4$12 \%$ of reproductive age women. ${ }^{3,4}$ The syndrome first defined by Stein and Leventhal in 1935, also referred to as Stein-Leventhal syndrome, and is one of the most common endocrinopathies. It is characterized by hyperandrogenism, abnormal ovarian morphology; atypical gonadotropin secretions, hyperinsulinemia, peripheral insulin resistance and irregular anovulatory bleeding. Clinical manifestations of PCOS include oligomenorrhea/amenorrhea, infertility/first trimester miscarriage, obesity, hirsutism, acne, acanthosis nigricans and male pattern alopecia. ${ }^{5}$ ESHRE/ASRM (Rotterdam criteria) 2004 defines PCOS by exclusion of other androgen excess or related disorders and includes two of 
the following: Clinical and/or biochemical hyperandrogenism, oligo- or chronic anovulation and polycystic ovaries. The various treatment options for infertile PCOS women are non- Pharmacological and includes life style modification, diet, exercise and weight loss and pharmacological which can be further divided into $-1^{\text {st }}$ line treatment: Clomiphene citrate, $2^{\text {nd }}$ line treatment: Laparoscopic ovarian drilling, Gonadotropins and 3rd line treatment: In- vitro fertilization.

Clomiphene resistance is common and occurs in approximately $15 \%-40 \%$ of women with PCOS. ${ }^{6}$ Clomiphene resistance is defined as failure to ovulate after receiving up to $150 \mathrm{mg}$ of clomiphene citrate (CC) daily for 5 days from 2 nd day of cycle for at least 3 menstrual cycles. If clomiphene citrate fails to result in pregnancy, the recommended second line intervention is either LOD or gonadotropins. ${ }^{7}$

LOD causes focal destruction of the ovarian stroma in an effort to decrease both intraovarian and systemic androgen concentrations. ${ }^{8}$ Postoperative serum concentrations of androstenedione and testosterone decreases at least for a time, and inhibin concentrations also decline. ${ }^{9}$ Both changes are likely contributed to an associated increase in FSH levels and thus ovulation. On the other hand, the mechanism of action of gonadotropins is to induce ovulation, maintain and provoke optimum follicle growth via the controlled administration of FSH and LH. ${ }^{10}$ Very few studies are available in literature which has been done in India on laparoscopic ovarian drilling and no comparative interventional Indian study has been found to address this very common and increasing problem of clomiphene resistant PCOS in women in a developing country like ours. Keeping this in mind, the present work has been planned with the aim to compare the clinical outcomes in clomiphene citrate resistant infertile PCOS women after treatment with LOD versus gonadotropins.

\section{METHODS}

Women between age group 20-35 years with complaints of infertility due to PCOS not responding to clomiphene citrate were recruited for present study following Rotterdam's criteria to diagnose PCOS. The subjects included in the study were randomly divided into two equal groups of 20 each after written informed consents. Detailed history was taken, and physical examination was done, which included anthropometric measurements like height $(\mathrm{m})$, weight $(\mathrm{kg})$, body mass index. This was followed by local examination (per-speculum and pervaginal examination) including cervix, uterine size, position and mobility of uterus, tenderness on uterine motion and in fornices. Pre-defined Performa was filled for all the patients. Baseline investigations like Complete Blood Count, haematocrit, blood sugar profile, HbA1c, urine analysis, liver and kidney function tests, thyroid function tests, Chest X-Ray, viral markers were done for all patients. Husband semen analysis (HSA) was done to rule out male factor of infertility.

Ultrasonography was done for all patients at time of presentation to measure the volume and calculate number of antral follicles in ovaries. USG criteria included presence of 12 or more follicles in each ovary measuring 2-9 $\mathrm{mm}$ in diameter and/or increased ovarian volume $(>10 \mathrm{ml})$ regardless of follicle distribution or ovarian stromal echogenicity. Hysterosalpingography (HSG) was done to rule out any uterine/tubal cause of infertility.

\section{Surgical approach for Laparoscopic Ovarian Drilling (Group A patients)}

After pre- operative assessment and allocation to LOD group, Pre-Anaesthetic Check-up and fitness was obtained. After due counselling and consent, the procedure was performed under general anaesthesia in all the patients. Adequate antibiotic prophylaxis was given. After painting, draping, per-speculum and per-vaginum examination were done and utero-cervical length was measured. Pneumoperitoneum was obtained by inserting Verres needle followed by trocar entry. A $5 \mathrm{~mm}$ umbilical port and two $5 \mathrm{~mm}$ ipsilateral/contra lateral ports in lower abdomen, one just above the anterior superior iliac spine and the other at the level of umbilicus $10 \mathrm{~cm}$ lateral to the midline were made. Inspection of the pelvis was done to rule out other factors related to infertility. Ovarian ligament was held with non-traumatic grasper to steady the ovary while doing the procedure. The mono polar needle was introduced at right angle to avoid injury to the hilum. 40 watts current was used to make 4 holes each lasting $4 \mathrm{sec}$ at a depth of $4 \mathrm{~mm}$ on both ovaries. Chromopertubation was done by transcervical injection of dilute methylene blue dye to reassess tubal patency. Thorough irrigation suction was done followed by hydrotubation and hydro floatation with $100 \mathrm{ml}$ Ringer lactate solution to minimize postoperative adhesions. Haemostasis was secured and all the trocars were removed under vision and examined for any port-site bleeding. Ports were closed after deflating pneumoperitoneum by staples followed by antiseptic dressing. Patient was called after one week for staples removal. Ovulation induction was done in next cycle with clomiphene citrate $100 \mathrm{mg}$ from day $2 / 3$ of cycle for 5 days followed by serial follicular monitoring by TVS along with E2 when required, for 2 cycles followed by $150 \mathrm{mg}$ of $\mathrm{CC}$, if required. Injection Human chorionic gonadotropin (hCG;5000 international units) was given intramuscularly if follicle size $\geq 17 \mathrm{~mm}$ and intra uterine insemination (IUI) was planned between 36 to 42 hours post injection hCG, whenever indicated.

\section{Medical management (Group B patients)}

After due counselling and consents, patients with day $2 / 3$ endometrial thickness (ET) $\leq 5 \mathrm{~mm}$ on TVS were recruited to medical management group. Urinary gonadotropins or recombinant FSH 50-75 IU was given on daily basis for 5 
days (day $2 / 3$ to day $6 / 7$ ) depending on BMI. On day $7 / 8$ of cycle, serum estradiol (E2) level with serial follicular monitoring by TVS was done to measure for direct assessment of number and size of growing follicles as well as their growth rate and endometrial thickness. Thereafter, the dose of gonadotropins was maintained or increased according to folliculometry on TVS. Once the serum E2 begun to rise, frequency of evaluation increased to every 1-2 days. If terminal E2 $>1200 \mathrm{pg} / \mathrm{ml}$ or $>3$ dominant follicles $(\geq 17 \mathrm{~mm})$, the cycle was abandoned to prevent ovarian hyper-stimulation syndrome and multiple pregnancy. Injection human chorionic gonadotropin (hCG; 5000 international units) was given intramuscularly if $<3$ dominant follicles on TVS and serum E2 $<1200 \mathrm{pg} / \mathrm{ml}$ and IUI was planned between 36 to 42 hours post hCG trigger, whenever indicated. Patients were treated further two subsequent cycles of gonadotropins if indicated.

\section{Method of measurement of outcomes of interest}

- Transvaginal ultrasound documentation of ovulation: The changes in ultrasound image of follicles that ruptured were-disappearance or sudden decrease in size, irregularity of follicular wall, appearance of free fluid in cul de sac of Douglas and hyperechogenic secretory endometrium.

- Urine pregnancy test: Urine pregnancy test was done after two weeks of natural contact/IUI

- Serum beta hCG: To confirm the pregnancy, serum beta hCG was done in patient with positive urine pregnancy test. If the level of serum beta hCG was more than $25 \mathrm{mIU} / \mathrm{ml}$ then pregnancy was confirmed.

- Ultrasound (TAS/TVS): To confirm pregnancy, and differentiate singleton pregnancy from multiple pregnancies.

\section{Statistical analysis}

Statistical testing was conducted with the statistical package for the social science system version SPSS 17.0. Continuous variables are presented as mean $\pm \mathrm{SD}$, and categorical variables are presented as absolute numbers and percentage. The comparison of normally distributed continuous variables between the groups was performed using Student's t-test. Nominal categorical data between the groups were compared using Chi-squared test or Fisher's exact test as appropriate. $\mathrm{P}<0.05$ was considered statistically significant.

\section{RESULTS}

Clomiphene citrate resistant infertile PCOS women were assessed according to the inclusion and exclusion criteria and divided randomly into two equal groups of 20 participants each for laparoscopic ovarian drilling (Group A) and gonadotropins (Group B). They were further assessed for various demographic variables and the outcome measures.
Table 1: Age distribution of women.

\begin{tabular}{|c|c|c|c|c|}
\hline $\begin{array}{l}\text { Age group } \\
\text { (years) }\end{array}$ & Group A & Group B & Total & $\begin{array}{l}P \\
\text { value }\end{array}$ \\
\hline $20-24$ & $3(15 \%)$ & $3(15 \%)$ & $\begin{array}{l}6 \\
(30 \%)\end{array}$ & \\
\hline $25-29$ & $8(40 \%)$ & $12(60 \%)$ & $\begin{array}{l}20 \\
(100 \%)\end{array}$ & 0.404 \\
\hline $30-35$ & $9(45 \%)$ & $5(25 \%)$ & $\begin{array}{l}14 \\
(80 \%)\end{array}$ & \\
\hline Mean \pm SD & $28.45 \pm 3.620$ & $27.55 \pm 3.103$ & $28 \pm 3.36$ & \\
\hline
\end{tabular}

Majority of women belonged 25-29 years of age group. Both the groups were found to be comparable in terms of this demographic variable $(\mathrm{P}=0.404)$.

Table 2: Duration of infertility.

\begin{tabular}{|c|c|c|c|c|}
\hline $\begin{array}{l}\text { Duration } \\
\text { of years }\end{array}$ & Group A & Group B & Total & $\begin{array}{l}p \\
\text { value }\end{array}$ \\
\hline $1-2.9$ & $5(25 \%)$ & $4(20 \%)$ & $9(22 \%)$ & \multirow{5}{*}{0.603} \\
\hline $3-4.9$ & $7(35 \%)$ & $10(50 \%)$ & $17(42.5 \%)$ & \\
\hline $5-7.9$ & $7(35 \%)$ & $3(15 \%)$ & $10(25 \%)$ & \\
\hline $8-12$ & $1(5 \%)$ & $3(15 \%)$ & $4(10 \%)$ & \\
\hline Mean \pm SD & $4.17 \pm 1.886$ & $4.57 \pm 2.843$ & $4.37 \pm 2.39$ & \\
\hline
\end{tabular}

Majority of the women had infertility of 3-7.9 years duration.

Both the groups in present study were found to be comparable with respect to mean duration of infertility (P: 0.603) and there was no significant difference found between the two groups.

Table 3: Clinical features.

\begin{tabular}{|llll|}
\hline $\begin{array}{l}\text { Clinical } \\
\text { features }\end{array}$ & Group A & Group B & Total \\
\hline $\begin{array}{l}\text { Menstrual } \\
\text { dysfunction }\end{array}$ & $\begin{array}{l}20 \\
(100 \%)\end{array}$ & $20(100 \%)$ & $40(100 \%)$ \\
\hline Acne & $10(50 \%)$ & $10(50 \%)$ & $20(50 \%)$ \\
\hline Hirsutism & $9(45 \%)$ & $10(50 \%)$ & $19(47.5 \%)$ \\
\hline $\begin{array}{l}\text { Acanthosis } \\
\text { nigricans }\end{array}$ & $3(15 \%)$ & $8(40 \%)$ & $11(27.5 \%)$ \\
\hline
\end{tabular}

Most common symptom in both groups was menstrual irregularities. $100 \%$ of patients in LOD (Group A) and $100 \%$ in Gonadotropins (Group B) had this complaint. Most common sign was acne which was seen in $50 \%$ in LOD group and 50\% in gonadotropins group followed by hirsutism and pigmentation (acanthosis nigricans).

Table 4: Mean antral follicle count.

\begin{tabular}{|llll|}
\hline & Group A & Group B & p value \\
\hline $\begin{array}{l}\text { Mean antral } \\
\text { follicle count }\end{array}$ & $26.75 \pm 4.25$ & $27.90 \pm 3.19$ & 0.340 \\
\hline
\end{tabular}

Both the groups in present study were found to be comparable with respect to mean antral follicles count $(\mathrm{P}=0.340)$. 
Table 5: Mean ovarian volume.

\begin{tabular}{|llll|} 
& Group A & Group B & p value \\
$\begin{array}{l}\text { Mean ovarian } \\
\text { volume }\left(\mathrm{cm}^{3}\right)\end{array}$ & $14.99 \pm 2.87$ & $13.96 \pm 2.39$ & 0.223 \\
\hline
\end{tabular}

Both the groups in present study were found to be comparable with respect to mean ovarian volume in both group $(\mathrm{P}=0.223)$.

Table 6: Comparison of ovulation rate per cycle.

\begin{tabular}{|llll|}
\hline Ovulation & Group A & Group B & p value \\
\hline $1^{\text {st }}$ cycle & $12(60 \%)$ & $16(80 \%)$ & 0.301 \\
\hline $2^{\text {nd }}$ cycle & $12(63.15 \%)$ & $12(80 \%)$ & 0.451 \\
$3^{\text {rd }}$ cycle & $11(68.75 \%)$ & $9(69.23 \%)$ & 1.000 \\
\hline
\end{tabular}

Table 7: Comparison of cumulative ovulation rate in both groups.

\begin{tabular}{|llll|}
\hline Ovulation & Group A & Group B & p value \\
\cline { 1 - 3 } Yes & $16 / 20(80 \%)$ & $18 / 20(90 \%)$ & \multirow{2}{*}{0.661} \\
\hline No & $4 / 20(20 \%)$ & $2 / 20(10 \%)$ & \\
\hline
\end{tabular}

Ovulation was a major outcome measure in present study. 16 women $(80 \%)$ in LOD (Group A) with clomiphene citrate and 18 women (90\%) ovulated in gonadotropins (Group B). The difference was not statistically significant $(\mathrm{P}=0.661)$ in both groups

Table 8: Comparison of pregnancy rate per cycle.

\begin{tabular}{|llll|}
\hline Pregnancy & Group A & Group B & p value \\
\hline $1^{\text {st }}$ cycle & $1 / 12(8.3 \%)$ & $5 / 16(31.25 \%)$ & 0.197 \\
\hline $2^{\text {nd }}$ cycle & $3 / 12(25 \%)$ & $2 / 12(16.66 \%)$ & 1.000 \\
\hline $3^{\text {rd }}$ cycle & $0 / 11(0 \%)$ & $2 / 9(22.22 \%)$ & 0.189 \\
\hline
\end{tabular}

Table 9: Comparison of pregnancy rate per cycle.

\begin{tabular}{|lll|l|}
\hline Pregnancy & Group A & Group B & p value \\
\hline Yes & $4(20 \%)$ & $9(45 \%)$ & 0.176 \\
\hline No & $16(80 \%)$ & $11(55 \%)$ & \\
\hline
\end{tabular}

Pregnancy was the second major outcome in present study. 4 women (20\%) in LOD (Group A) with clomiphene citrate got pregnant and 9 women (45\%) got pregnant in gonadotropins (Group B). The difference was not statistically significant $(\mathrm{P}=0.176)$ in both groups.

Table 10: Comparison of complications in both the groups.

\begin{tabular}{|llll|}
\hline Complications & Group A & Group B & p value \\
\hline Multiple pregnancy & $0(0 \%)$ & $2(10 \%)$ & 0.487 \\
\hline Cycle cancelled & $0(0 \%)$ & $3(15 \%)$ & 0.231 \\
\hline OHSS & $0(0 \%)$ & $0(0 \%)$ & - \\
\hline
\end{tabular}

OHSS- ovarian hyperstimulation syndrome

There were no complications seen in LOD (Group A). None of women had OHSS in both groups. The difference between the two groups was not found to be statistically significant $(\mathrm{P} 1=0487, \mathrm{P} 2=0.231)$.

\section{DISCUSSION}

Present study titled was conducted at Sir Ganga Ram Hospital, New Delhi, from March 2015 to September 2016. A total of 40 women were enrolled in the study. We found no statistically significant difference in ovulation and pregnancy rates with either laparoscopic ovarian drilling or gonadotropins. In present study, the mean age (Table 1) in Group A was 28.45 \pm 3.620 years while the mean age in Group B was 27.55 \pm 3.103 years. In the study done by Mehrabian et al, the mean age in laparoscopic ovarian drilling group was $29.17 \pm 5.47$ years whereas in gonadotropins group was 28.51 \pm 5.51 years comparable to present study. ${ }^{11}$ The mean duration of infertility (Table 2) in Group A was 4.17 \pm 1.886 years while the mean duration in Group B was $4.57 \pm 2.843$ years. Kamel et al, reported that the mean duration of infertility in laparoscopic ovarian re-drilling group was $5.6 \pm 2.1$ years, whereas in gonadotropins group, it was $4.7 \pm 2.1$ years similar to present study. ${ }^{12}$ Menstrual dysfunction was the chief presenting complaint (Table 3) in majority of literature available on comparative studies done between LOD and gonadotropins in infertile PCOS women. Ramanand et al did a study on clinical characteristics of PCOS in Indian women and reported menstrual irregularities as the chief complaint in $100 \%$ of women, $44.16 \%$ patients showed presence of acanthosis nigricans and $44.16 \%$ women had hirsutism. ${ }^{13}$

Antral follicles count is a potentially useful predictor of the outcome of ovarian stimulation in PCOS women. ${ }^{14}$ Kandil et al did a study on sonographic assessment of ovarian reserve before and after laparoscopic ovarian drilling in PCOS and reported pre-treatment mean antral follicles count in LOD group was $16.5 \pm 1.3 .{ }^{15}$ This aspect was not analysed in gonadotropins group in majority of studies available on the subject. In LOD group, pretreatment mean antral follicle count was $26.75 \pm 4.25$ and in gonadotropins group it was $27.90 \pm 3.19$. $(\mathrm{P}=0.340)$, in present study as depicted in Table 4. Ovarian volume correlates with ovarian response to stimulation, and thus one of the important parameters to assess ovarian reserve as well. Table 5 depicts that both groups were found to be comparable with respect to mean ovarian volume. $(\mathrm{P}=0.223)$. Mehrabian et al reported mean ovarian volume in LOD group was $11.3 \pm 5.5 \mathrm{~cm}^{3} .{ }^{16}$ Mean ovarian volume was not analysed in gonadotropins group in majority of studies available on this subject.

In Table 6 and 7 it is seen that, in Group A after giving 1st cycle of CC, $12(60 \%)$ women ovulated. $2^{\text {nd }}$ cycle of $\mathrm{CC}$ included 19 women $(\mathrm{n}=19)$ who did not get pregnant in 1 st cycle. Out of these 19 women, $12(63.15 \%)$ women ovulated. In 3rd cycle of CC, total number of women who did not get pregnant in 1 st and $2^{\text {nd }}$ cycle were $16(n=16)$. Out of these 16 women, $11(68.75 \%)$ women ovulated. In present study it was found that the sensitivity of $\mathrm{CC}$ 
improved after LOD in CC resistant infertile women. Palomba et al did a randomized controlled trial in 2010 to compare the effect of metformin plus CC with LOD for ovulation induction in $\mathrm{CC}$ resistant infertile PCOS women and reported ovulation rate in LOD plus CC group was $68.2 \%$ per cycle. ${ }^{17}$ Kamel et al reported ovulation rate with 3 stimulated cycles of $\mathrm{CC}$ in laparoscopy ovarian re-electro-cautery group was 6 (20\%), $8(26.6 \%)$ and $2(6.7 \%)$ in 1 st, 2nd and 3rd cycle respectively. ${ }^{12}$ In present study, in Group B after giving 1 st cycle of gonadotropins, $16(80 \%)$ women ovulated. 2nd cycle of gonadotropins included 15 women who did not get pregnant in 1 st cycle. Out of these 15 women, 12 $(80 \%)$ women ovulated. In $3^{\text {rd }}$ cycle of gonadotropins, total number of women who did not get pregnant in 1 st and $2^{\text {nd }}$ cycle was 13 . Out of these 13 women, $9(69.23 \%)$ women ovulated. Ovulation rate per cycle was not analysed separately in gonadotropins group in majority of studies available on subject. Ovulation was thus, a major outcome measured in present study, but the difference between ovulation rate was not statistically significant $(\mathrm{P}=0.661)$ in both the groups. Cumulative ovulation rate with LOD followed by CC was $81.5 \%$ in a study done by Roy et al. ${ }^{18}$ Bayram et al reported cumulative rate of ovulation of six cycles in LOD plus CC group was $45 \%$ where as in gonadotropins group it was $69 \% .{ }^{19}$ In a study done by Kato et al on efficacy of LOD for CC resistant PCOS patients and reported cumulative ovulation rate as $23 / 32(71.8 \%)$ in women who were treated with LOD followed by $\mathrm{CC}{ }^{20}$ Malkawi et al reported, $83.5 \%$ ovulation rate in LOD plus CC group and successful ovulation rate of $70.6 \%$ and $66.7 \%$ with human menopausal gonadotropins (hMG) and pure follicle stimulating hormone (FSH) respectively. ${ }^{21,22}$ In present study, inGroup A, out of 12 ovulated women in 1st cycle, $1(8.3 \%)$ got pregnant. In $2^{\text {nd }}$ cycle of CC, out of total 12 ovulated women, 3 (25\%) got pregnant.

In $3^{\text {rd }}$ cycle of $\mathrm{CC}$, out of these 11 ovulated women, none of women got pregnant.

Kamel et al, reported pregnancy rate in ovarian re-drilling group as $0(0 \%), 2(8 \%)$ and $0(0 \%)$ by 3 stimulated cycles of $\mathrm{CC}$ in $1^{\text {st }}, 2^{\text {nd }}$ and $3^{\text {rd }}$ cycle respectively and pregnancy rate per cycle was $2.2 \% .{ }^{12}$ In present study, in Group B, out of the 16 ovulated women in 1 st cycle, 5 $(31.25 \%)$ got pregnant. In $2^{\text {nd }}$ cycle of gonadotropins, out of total 12 ovulated women, $2(16.66 \%)$ got pregnant and in 3rd cycle of gonadotropins, out of the 9 ovulated women, 2 (22.22\%) got pregnant (Table 8 and 9). Kamel et al reported, pregnancy rate per cycle was $5.7 \%$ in group stimulated by purified FSH for 3 cycles. ${ }^{12}$ The difference in pregnancy outcome was not statistically significant $(\mathrm{P}=0.176)$ in both the groups. Bayram et al reported cumulative rate of pregnancy in LOD plus CC group as $49 \%$ where as in gonadotropins group it was 67\%. ${ }^{19}$ Malkawi et al reported pregnancy rate in LOD plus CC group as $59.8 \%$ and cumulative pregnancy rate in human menopausal gonadotropins (hMG) and pure follicle stimulating hormone (FSH) groups were $55.4 \%$, and $38.3 \%$ respectively. ${ }^{21,22}$ Goudarzi et al found that there was no evidence of a statistically significant difference in pregnancy rate when LOD compared with gonadotropins (OR: 0.534; 95\% CI: 0.242-1.176, $\mathrm{p}=0.119,6$ trials, 499 women, $\mathrm{I} 2=73.201 \%) .{ }^{23}$ Mitra et al did a study on role of LOD in management of PCOS and reported that LOD was as effective as gonadotropins in terms of pregnancy and live birth rates, but without the risks of ovarian hyper-stimulation syndrome and multiple pregnancies. $^{24}$

\section{CONCLUSION}

In present study, we found that the ovulation rates were comparable in both the groups; that is $80 \%$ in laparoscopic ovarian drilling (LOD) group and $90 \%$ in gonadotropins induction group. The pregnancy rates in the gonadotropins group were although numerically higher than LOD group, (20\% in LOD group and $45 \%$ in gonadotropins group) there was no statistically significant difference found.

Gonadotropins group had the advantage of being a nonsurgical technique with good results but the risks of multiple pregnancies; ovarian hyperstimulation syndrome (OHSS) and cycle cancellation due to excessive number of dominant follicles formed were higher than LOD group. The cycle also required an intensive and complex monitoring.

Laparoscopic ovarian drilling on the other hand had the advantages of providing an opportunity to assess the pelvic organs including evaluation of tubal patency, tuboovarian relations, to rule out any pelvic pathology and a cost effective one time treatment, but the disadvantage of being a surgical procedure with the associated risks and morbidity (Although no such complications were observed in present study group).

To conclude, both laparoscopic ovarian drilling and gonadotropins are equally effective treatment options for clomiphene citrate resistant infertile polycystic ovarian syndrome women, each having their own advantages and disadvantages. The treatment option can be selected and tailored according to the individual needs and desires of the patient.

\section{Funding: No funding sources}

Conflict of interest: None declared

Ethical approval: The study was approved by the Institutional Ethics Committee

\section{REFERENCES}

1. Boivin J, Bunting L, Collins JA, Nygren KG. International estimates of infertility prevalence and treatment-seeking: potential need and demand for infertility medical care. Hum Reprod. 2007;22:150612. 
2. Novak E, Berek JS. Berek and Novak's gynecology. Lippincott Williams and Wilkins;2007.

3. Knochenhauer ES, Key TJ, Kahsar-Miller M, Waggoner W, Boots LR, Azziz R. Prevalence of the polycystic ovary syndrome in unselected black and white women of the southeastern United States: a prospective study. J Clin Endocrinol Metab. 1998;83:3078-3082.

4. Farah L, Lazenby AJ, Boots LR, Azziz R. Prevalence of polycystic ovary syndrome in women seeking treatment from community electrologists. Alabama Professional Electrology Association Study Group. J Reprod Med. 1999;44:870-4.

5. Sheehan MT. Polycystic ovarian syndrome: diagnosis and management. Clin Med Res. 2004;2:13-27.

6. Brown J, Farquhar C, Beck J, Boothroyd C, Hughes E. Clomiphene and anti-oestrogens for ovulation induction in PCOS. Cochrane Database Syst Rev. 2009 Oct 7;(4):CD002249.

7. ACOG Committee on Practice BulletinsGynecology. ACOG Practice Bulletins No.108: Polycystic ovary syndrome. Obstet Gynecol. 2009;114:936-49.

8. Speroff L, Fritz MA. Induction of ovulation. In: Speroff L, Fritz MA, editors. Clinical Gynecologic Endocrinology and Infertility. $8^{\text {th }}$ ed. Lippincott Williams and Wilkins;2011:1293-1330.

9. Flyckt RL, Goldberg JM. Laparoscopic ovarian drilling for clomiphene resistant polycystic ovary syndrome. Semin Reprod Med. 2011;29:138-46.

10. Badawy A, Elnashar A. Treatment options for polycystic ovary syndrome. Int J Women's Health. 2011;3:25-35.

11. Saleh AM, Khalil HS. Review of nonsurgical and surgical treatment and the role of insulin-sensitizing agents in the management of infertile women with polycystic ovary syndrome. Acta Obstet Gynecol Scand. 2004;83:614-21.

12. Kamel MA, Abdel Hamid AE, Abdel-Rahim M, Mostafa SA. Laparoscopic ovarian re-electro cautery versus ovulation induction with $\mathrm{FSH}$ for persistant anovulation after laparoscopic PCOS treatment. Middle East Fertil Soc J. 2004;9:71-8.

13. Ramanand SJ, Ghongane BB, Ramanand JB, Patwardhan MH, Ghanghas RR, Jain SS. Clinical characteristics of polycystic ovary syndrome in Indian women. Indian $\mathrm{J}$ Endocrinol Metab. 2013;18:221-5.

14. El-Mazny A, Abou-Salem N. Anti-Müllerian hormone and antral follicle count for prediction of ovarian stimulation response in polycystic ovary syndrome. Gynecol Endocrinol. 2013;29:826-9.

15. Kandil M, Selim M. Hormonal and sonographic assessment of ovarian reserve before and after laparoscopic ovarian drilling in polycystic ovary syndrome. BJOG. 2005;112:1427-30.
16. Mehrabian F, Eessaei F. The laparoscopic ovarian electrocautery versus gonadotropin therapy in infertile women with clomiphene citrate-resistant polycystic ovary syndrome; a randomized controlled trial. J Pak Med Assoc. 2012;62:42-4.

17. Palomba S, Orio F Jr, Falbo A, Russo T, Caterina G, Manguso $F$ et al. Metformin administration and laparoscopic ovarian drilling improve ovarian response to clomiphene citrate (CC) in oligoanovulatory $\mathrm{CC}$-resistant women with polycystic ovary syndrome. Clin Endocrinol (Oxf). 2005;63:631-5.

18. Roy KK, Baruah J, Moda N, Kumar S. Evaluation of unilateral versus bilateral ovarian drilling in clomiphene citrate resistant cases of polycystic ovarian syndrome. Arch Gynecol Obstet. 2009;280:573-8.

19. Bayram N, Van Wely M, Kaaijk EM, Bossuyt PM, van der Veen F. Using an electrocautery strategy or recombinant follicle stimulating hormone to induce ovulation in polycystic ovary syndrome: randomised controlled trial. BMJ. 2004;328: 192-195.

20. Kato M, Kikuchi I, Shimaniki H, Kobori H, Aida T, Kitade M, et al. Efficacy of laparoscopic ovarian drilling for polycystic ovary syndrome resistant to clomiphene citrate. J Obstet Gynaecol Res. 2007;33:174-80.

21. Malkawi HY, Qublan HS, Hamaideh AH. Medical vs. surgical treatment for clomiphene citrate-resistant women with polycystic ovary syndrome. J Obstet Gynaecol. 1990;33:585-92.

22. Malkawi HY, Qublan HS, Hamaideh AH. Medical vs. surgical treatment for clomiphene citrate-resistant women with polycystic ovary syndrome. J Obstet Gynaecol. 2003;23:289-93.

23. Moazami Goudarzi Z, Fallahzadeh H, Aflatoonian A, Mirzaei M. Laparoscopic ovarian electrocautery versus gonadotropin therapy in infertile women with clomiphene citrate-resistant polycystic ovary syndrome: A systematic review and meta-analysis. Iran J Reprod Med. 2014;12:531-8.

24. Mitra S, Nayak PK, Agrawal S. Laparoscopic ovarian drilling: An alternative but not the ultimate in the management of polycystic ovary syndrome. $\mathrm{J}$ Nat Sci Biol Med. 2015;6:40-8.

Cite this article as: Rupa K, Jain K, Dutta D, Gupta SM, Chopra K. Comparison of clinical outcomes in clomiphene citrate resistant infertile polycystic ovarian syndrome women after treatment with laparoscopic ovarian drilling (LOD) versus gonadotropins. Int J Reprod Contracept Obstet Gynecol 2018;7:576-81. 